During the next few days, however, the temperature gradually fell, as also did the pulse rate and the respiration rate.

From a careful consideration of the history of the case and of the symptoms present a diagnosis of temporo-sphenoidal abscess was made and operation advised. It was agreed, however, to open the mastoid process first and examine carefully for any fistulous track which might snow the path of propagation to the intcrior of the cranium. The patient was accordingly put under chloroform, and the mastoid, antrum, the attic, and the roof of the middle ear carefully exposed and examined by means of a limelight search apparatus. No fistulie were, however, found. Owing to the collapsed state of the patient at the end of this examination it was decided to postpone opening the cranial cavity. The patient was accordingly put back to bed, warm bottles were placed round the body, and weak warm brandy and water was given internally. Two days afterwards the patient was again put under chloroform-very little, however, being used owing to her continued weak and collapsed condition. At this time the temperature was $97^{\circ} 4^{\circ} \mathrm{Fahr}$., the pulse 60 , and the respirations $\mathrm{I} 6$. The scalp was rapidly reflected around the ear and all bleeding points at once ligatured. A disc of bone was now removed one and a half inches behind and above the centre of the external auditory meatus (Reid's base line). Upon its removal the dura at once bulged into the opening, and no pulsation of the brain was visible. A small opening was now made through the dura and a pus searcher driven directly into the temporosphenoidal lobe. After having penetrated the cortex for about half an inch pus oozed out. In all about three drachms of intensely fotid darkcoloured and thick pus escaped. A rubber drainage tube was at once slipped into the abscess cavity, which was then thoroughly irrigated with a warm solution of boracic acid. The head was then dressed in the usual way. The patient made an uninterrupted recovery, the tube being removed upon the fourtcenth day. When seen a few days ago-now five months after the operation-perfect healing was found, both as regards the wound in the head and as regards the cuticularization of the cavity formed by throwing the middle ear, the external meatus, the attic, and the antrum into one. The patient's general health is now excellent, and she is able to carry on her work - that of a hard-working and busy dressmaker.

\title{
THREE INTERESTING CASES OF FOREIGN BODIES IN THE AIR PASSAGES.
}

\author{
By H. P. Meyjes, M.D.,
}

Private Lecturer at the University in Amsterdam.

QUITE recently I had another proof of the danger incurred by the feminine custom of putting pins and needles into the mouth.

When eating (!), Miss B., aged twenty-one, had put a needle into her mouth, which, by the motion she made when swallowing, entered and fixed itself in the larynx. 
At once the patient felt a stinging pain about the larynx-chiefly at the right side. In the greatest trouble, the patient and her friends called for medical assistance. It was stated that there was a needle in the larynx; and the patient was told to come and see me, in order to have the corpus alienum extracted. A few hours after the accident the patient appeared before me. Present state was as follows: the patient is somewhat nervous, but is speaking in the normal way, complains of stinging pain in the throat, and points with her finger to the right cartilago thyroidea.

The respiration is normal-somewhat superficial ; there is no dyspnœa present; but every motion made in swallowing causes the pain to increase. Upon examination by means of the laryngoscopic mirror,

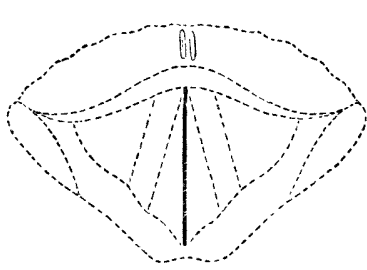

I found that the rather thick sewing needle had fastened itself exactly sagittally in the larynx-between the anterior commissure on one side and the cartilagines arytenoidx on the other. In phonation the vocal cords are quite close to the needle, whilst the mucous membrane, near the wounded point, is somewhat swollen and red. As the length of the needle was supposed to be three centimetres, I was quite aware that the extraction would present some difficulties, as, by repeated swallowing, the end had deeply penetrated into the tissue.

I thought of a somewhat similar case I saw, some time ago, in Schmitzler's clinic at Vienna. The swallowed needle ran from behind, at the right to the left, somewhat over the rima glottidis, leaving the vocal cords untouched. The reactive inflammation-probably caused by resultless efforts to extract-prevented the extraction in toto of the needle, of which only one centimètre was visible. The needle-which, happily, chanced to be rather thin-was, with some pains, cut in two in the middle of the free part, and both parts were extracted-the one after the other. Considering the difficulties connected with this mode of operation, I wanted to try first, if possible, to extract the needle in toto.

I tried to make out in what direction the point of the needle was; and I thought I might suppose that the somewhat thinner part was in the direction of the back part of the larynx. After cocainization of the pharynx and larynx with a ten per cent. solution, and directed by the laryngoscopic mirror, and by means of a strongly curved long forceps with oblique action, I took firmly hold of the needle in the middle; and, in order to disengage the thicker upper end, l pressed it deeper back into the tissue, and was happy to produce it at once in toto. The patient's spasmodic motions had not given me any difficulty, as the taking and extracting of the needle had been done almost in one single tempo. Precautionally, I showed the whole needle complete, both to the patient and her friends, as the sensation that remains for some time after the presence of corfora aliena in the air passages very often causes patients to believe there is still something sticking.

Now I could perfectly discover the two holes the needle made, and which were straight opposite the one to the other. By rest and anti-phlogistics the cure was sonn completed, and there remained no parasthesia.

The number of cases when patients have swallowed some object or 
another is rather great, and we are often astonished when seeing the really exceptional position of the corpus alienum. So of late I extracted a fish-bone which was almost strung to the mucous membrane of the right cartilage arytenoidea. The reaction had become already very important, and the voice was hoarse, as, in consequence of the swelling, a complete adduction of the vocal cords was not possible.

I thought the above case interesting enough for communication, especially by reason of the very peculiar position of the needle, both the ends having pierced the tissue, total absence of dysphonia, and the particular difficulties that may now and then complicate such kinds of extractions.

Another analogous case, of somewhat different character, brought the patient in great dangrer of his life.

A man aged thirty-five got a fish-bone in his throat and applied to me for assistance. The most scrupulous examination did not allow me to find even the slightest appearance of any corpus alienum. A week afterwards I was sent for by the patient, who for some days was suffering from heavy oppressiveness, together with heightened temperature and fotid expectoration. The patient was in a state of the utmost exhaustion. At once I supposed an abscess was forming itself, caused by the corpus alienum. Upon examination, by means of the laryngoscopical mirror, I discovered what follows:-Exactly over the entrance to the larynx, and almost entirely obstructing the opening, there is a tumour as large as a hen's egro, beginning from the back side of the pharynx and covering a great part of it. Upon digital examination the tumour appears to fluctuate, and the explorating finger was covered with thin and very fotid pus. Directed by the laryngoscopic mirror, the abscess is split up and down over the whole length, about four centimètres, which causes a mouthful of stinking pus to be spat out. At further examination no fishbone is found. The patient has a quiet night; the next morning he has no fever, and in a week he is completely cured. So thus the patient was for some days in danger of his life ; firstly, as by the increasing extent of the abscess the entrance to the larynx was by-and-bye closing, and, secondly, as a spontaneous breaking of the abscess would probably have caused an infectious inflammation of the lungs. We may suppose the fish-bone to have been very small, and by swallowing to have entirely penetrated into the tissue, as upon first examination the top of the finger did not find any protuberance on the pharynx.

From this case I saw how important it is, if the result of any first examination should prove negative, to repeat the examination for some time, even daily.

That corpora aliena lodged in the throat may readily cause a fever and fortid expectoration, I found by a third case, where a lady of forty. five, when eating chicken soup, got a bone in the throat. As she was very nervous, and had previously, without any special reason, repeatedly complained of itchings in the throat, her complaints were considered to be of very little importance. After three days she had a ferer, fetor $e x$ ore, and heary irradiate pain in the right upper arm. The physician prescribed salicylas natricus, as he thought she had an attack of rheumatism. The difficulty in swallowing continued. Then the patient was 
directed to me, and a laryngoscopic examination made by me found an object about two and a half centimètres, which had fastened itself in the tissue near the ligamentum glosso-epiglotticum lateral dextrum.

After the extraction, which was not over difficult, the pain in the arm ceased immediately, and after a few days also the fever and the foetor ex ore.

The corpus alienum appeared to be a little bone of a chicken, which, by having been for a rather long time fastened in the throat, had already caused an important reactive inflammation.

The most interesting character of this case was the heavy irradiate pain in the upper arm-a symptom which, indeed, is very rare, and which may be of importance for the diagnosis, if there is any corpus alienum present.

\section{SOCIETIES' MEETINGS.}

TWELFTH INTERNATIONAL MEDICAL CONGRESS, MOSCOW.

Second Day's Proceedings.-21st August, 1897.

(Continued from page 549.)

Dr. Gleirsmann in the Chair.

\section{Cancer of the Larynx.}

Prof. CHIARI based his "Report on the present position of the Diagnosis and Treatment of Carcinoma Laryngis" on the statistics and writings of others, and on seventy cases under his own observation. On twelve of these he had performed partial extirpation and on some others endolaryngeal operation. As Dr. Catti had undertaken to discuss diagnosis thoroughly, Chiari confined his remarks principally to the histological diagnosis and to treatment. With regard to microscopical examination, if the clinical appearances were in favour of cancer a negative histological result was of no value; but a positive microscopical result-provided the examiner was a competent experienced man-should always outweigh all negative clinical appearances. Several cases from his own experience were here cited in support of this view. Chiari next dealt at some length with the differential diagnosis between cancer and papilloma, pachydermia, tuberculosis, and syphilis, the general conclusion being that the only thoroughly reliable diagnostic method was microscopic cxamination.

Treatment.-One must consider first whether the patient is in a condition to stand a severe operation; second, whether there is hope of removing the whole of the diseased tissue. Endolaryngeal operations are, from a therapeutic point of view, of extremely doubtful value even when the disease is of small size and circumscribed. On the other hand, excision of portions of the growth for microscopic examination, in order to establish 